Viruses, wheezing, atopy and asthma

\section{Coughs and wheezes spread diseases: but what about the environment?}

A Bush

Interactions between viral infections, wheezing, atopy and asthma in children

O ne disagreeable part of growing up is the inevitable encounters with respiratory viruses which, in about half the population, will have led to at least one wheezing episode before school age. For many the symptoms of wheeze are trivial and require no or only intermittent treatment but, for others, winter in particular turns into a nightmare of recurrent hospital admissions punctuated by brief periods of perfect health before the next viral infection takes hold. All concerned feel powerless in both prevention and treatment; for many families it is inevitable that they use childcare facilities, a fertile virological breeding ground. In any case, the possible protective effects of viral infections against later asthma (below) should give pause for thought before removing the child from the crèche. Although there is some evidence that intermittent high dose inhaled corticosteroids $^{1}$ or oral montelukast ${ }^{2-4}$ may be adequate treatment, many children with viral associated wheeze end up being prescribed several courses of oral prednisolone each winter. The treatment of severe preschool viral induced symptoms is among the most taxing and least rewarding challenges in childhood wheezing disorders.

The hypothesis generating paper by Murray et al in this month's Thorax raises some hope for a potential new preventive approach. ${ }^{5}$ This group has extended previous work in adult asthmatics ${ }^{6}$-in which they showed an apparent synergy between viral infection, and allergen sensitization and exposure-into a group of unselected children with asthma, the youngest of whom were 3 years old. In a multivariate analysis they showed that children admitted to hospital with an asthma exacerbation (but not stable asthmatics or non-asthmatic controls) were significantly more likely to be infected with a respiratory virus and to have been exposed to an allergen to which they were sensitised. Before setting this study in context, it is worth rehearsing the relatively limited nature of the conclusions that can be drawn at the present time; like most of the best end of the paper than before the work started.

Firstly, although individually viral infection and allergen sensitisation and exposure were not significant in the multivariate analysis, the confidence intervals were wide and an increased risk of $>12$-fold and $>5$-fold, respectively, could have been missed. It would be wrong for the reader to conclude that the two together are always needed for an asthma exacerbation. Likewise, the absence of an effect of parental smoking probably reflects the age of the patients studied and might have been important in a younger age group. Secondly, the study group spans a wide age range and probably different wheezing phenotypes (see later). Finally, a longitudinal study is required to show that allergen avoidance will actually be of therapeutic benefit in reducing viral exacerbations of asthma; there have been too many surprises in the field of allergen avoidance to take anything for granted untested. It should also be noted that prophylactic inhaled corticosteroidsexcellent treatment for loss of asthma control-have proved dismally disappointing in the prevention of viral induced exacerbations, at least in preschool children, ${ }^{7}$ which is perhaps not what might have been predicted from these postulated interactions. A cross sectional study such as that performed by Murray et al can only show that taking (or, strictly speaking, being prescribed) inhaled corticosteroids is associated with a reduced risk of admission to hospital, but it is not necessarily the factor that is responsible for a reduction in admissions.

Nonetheless, what this paper does is to raise a series of testable hypotheses, particularly in the taxing field of preschool wheeze. This editorial sets the context for the findings of Murray et al in terms of childhood wheezing phenotypes and their potential modulation by viral infections and allergens, before discussing future studies needed to take forward the work in clinical practice. papers there are more questions at the

\section{PRESCHOOL WHEEZING PHENOTYPES}

A number of prospective cohort studies have delineated different patterns of preschool wheeze, sometimes called phenotypes. ${ }^{8-11}$ A phenotype may best be defined as the clinical expression of the interactions between an individual's genes and the environment, ${ }^{12}$ and these may be very complex. The concept of phenotypes may be more useful for exploration of mechanisms than in clinical practice because overlap syndromes are much more common than pure phenotypes. Nonetheless, cohort studies have drawn attention to patterns which may usefully guide treatment.

In general, wheeze with viral infections only, with onset in the first 2 years of life and no personal or family history of atopy, is likely to abate before school age. ${ }^{13}$ Lung function data would suggest that these infants are born with airflow obstruction but improve in the first 6 years of life. ${ }^{8}$ Atopy associated wheeze tends to have a later onset, is characterised by wheeze between viral colds, and persists into mid childhood. These infants probably have normal lung function at birth but develop airflow obstruction by the age of 6 years ${ }^{8}$ which persists at least into the late teenage years. ${ }^{14}$ Later onset non-atopic wheeze persisting into childhood is less usual and the aetiology is unclear. Pathological data are much scantier than physiological, but a recent study showed no evidence of airway inflammation or remodelling even in atopic infants with bronchodilator reversibility who underwent a bronchial biopsy at 1 year of age. ${ }^{15}$

In clinical practice, children frequently present with features of more than one pattern. The mechanisms that result in either regression or progression of symptoms are poorly understood but are of obvious importance. It is also clear that, in children aged less than 5 years, it should not be assumed that all wheezing disorders are similar to each other or to mid childhood and adult asthma, and this needs to be considered when testing hypotheses in this age group.

\section{VIRUSES AND WHEEZING}

There are a number of potential interactions between infants and respiratory viruses. It is indisputable that acute infections with rhinoviruses and respiratory syncytial virus (RSV) are a common cause of acute wheeze in infancy and childhood, irrespective of atopic status. Acute infection with adenovirus in particular can cause not only acute bronchiolitis but also later fixed airflow obstruction (obliterative bronchiolitis). Whether latent viral infection also occurs ${ }^{16}$ and causes later fixed "asthmatic" airflow obstruction is unknown. It is hypothesised that early 
viral infection can be protective against later asthma. In one study firstborn infants placed in a crèche had more wheezing episodes in the first year of life but fewer at 6 years of age than those looked after at home. An extra protective effect over and above that of sibship was not seen in infants with older siblings. ${ }^{17}$ The hypothesis (and it is only that) is that early virus infections are protective, perhaps by initiating or modulating a Th2 to Thl switch.

Can viral infections cause asthma and/ or allergen sensitisation? This question has been most studied in the context of RSV bronchiolitis. Although not all would agree, ${ }^{18}$ the best evidence is that, although symptoms of cough and wheeze after RSV bronchiolitis may persist into late childhood, they do abate and RSV does not cause asthma or an increased risk of atopy.$^{19}$ It is arguable that there is nothing special about RSV bronchiolitis, and the so-called "post-bronchiolitic syndrome" is no more than what is likely after any respiratory viral infection. Likewise, despite animal evidence suggesting that viral infections make allergic sensitisation more likely, ${ }^{20}$ there are no human data to support this concept.

\section{DO ALLERGENS CAUSE MORE THAN ALLERGY?}

Murray et al ${ }^{5}$ have studied allergic sensitisation as the mechanism whereby allergens cause harm, but this may be too narrow a focus. The same group, studying non-sensitised adults with asthma, showed that high levels of exposure to Can d l, but not Fel d l, were associated with worse bronchial hyperreactivity. ${ }^{2}$ The mechanism was unclear but was not IgE mediated. In theory there could have been some other host recognition mechanism or cross-reactivity with a host antigen which triggered airway damage, but it is more likely that the intrinsic properties of the allergen itself, independent of triggering an allergic reaction, were responsible. For example, Der $p \mathrm{l}$ is one of a number of proteolytic enzymes produced by the house dust mite which may potentially cause damage to the airway independent of allergic sensitisation. If that were the case, it raises the intriguing possibility that allergen avoidance may also be beneficial in the nonatopic virus associated wheeze phenotype.

\section{INTERACTIONS BETWEEN VIRUSES AND ALLERGENS}

In the very simplest terms, allergens in an allergic sensitised individual are likely to cause eosinophilic airway inflammation, whereas viruses would be predicted to cause airway neutrophilia or possibly neurogenic inflammation. ${ }^{22}$ If this is so, how do these disparate types of inflammation interact? And would the same effect be seen with other potential causes of airway neutrophilia such as cigarette smoke? It is known that active smoking induces a state of relative steroid resistance, ${ }^{23-25}$ might it also worsen the effects of allergen exposure to contribute to asthma exacerbations? Could passive smoking have the same effect?

\section{FUTURE WORK}

Where does the work by Murray et al take us? Clearly, the next step is an intervention study. One possible design, akin to a recent trial of steroids in preschool children, ${ }^{26}$ would be to randomise children admitted to hospital with a proven viral exacerbation of asthma to an allergen avoidance programme or placebo measures. Although it would be important to document allergic sensitisation prospectively by skin prick testing, I would include non-atopic and non-sensitised children in the study with a planned subgroup analysis of this group. It would be important to examine the pattern of wheezing (only virus associated $v$ viral and interval wheeze) and also the success (or otherwise) of the allergen exclusion measures. The potential importance of cigarette smoke exposure should not be forgotten, particularly in younger patients; by analogy with occupational asthma, passive smoke may unfavourably modulate the interactions (in the broadest sense) between allergens and airways. I would try to use objective measures of lung function; even some quite young children can perform spirometry ${ }^{27}$ and other lung function tests. ${ }^{28}$ If it could be shown that allergen avoidance reduced viral exacerbations in both atopic sensitised and non-atopic children, particularly in the preschool age group, that would indeed be a major advance.

Thorax 2006;61:367-368

doi: $10.1136 /$ thx.2005.048389

Correspondence to: Professor A Bush, Department of Paediatric Respiratory Medicine, Royal Brompton Hospital, Sydney Street, London SW3 6NP, UK; a.bush@rbh.nthames. nhs.uk

\section{REFERENCES}

1 McKean M, Ducharme F. Inhaled steroid for episodic viral wheeze of childhood. Cochrane Database Syst Rev 2000;(2):CD001 107.

2 Knorr B, Franchi LM, Bisgaard $\mathrm{H}$, et al. Montelukast, a leukotriene receptor antagonist, for the treatment of persistent asthma in children aged 2 to 5 years. Pediatrics 2001;108:E48.

3 Bisgaard $\mathbf{H}$. A randomised trial of montelukast in respiratory syncytial virus postbronchiolitis. Am J Respir Crit Care Med 2003; 167:379-83.

4 Robertson CF, Henry RL, Mellis C, et al. Short course montelukast for intermittent asthma in children: the Pre-empt study. Am J Respir Crit Care Med 2004; 169:A149.

5 Murray CS, Poletti G, Kebadze T, et al. Study of modifiable risk factors for asthma exacerbations: virus infection and allergen exposure increase the risk of asthma hospital admissions in children. Thorax 2006;61:376-82.
6 Green RM, Custovic A, Sanderson G, et al. Synergism between allergens and viruses and risk of hospital admission with asthma: case-control study. BMJ 2002;324:763-6.

7 Wilson N, Sloper K, Silverman M. Effect of continuous treatment with topical corticosteroid on episodic viral wheeze in preschool children. Arch Dis Child 1995;72:317-20.

8 Martinez FD, Wright AL, Taussig LM, et al. Asthma and wheezing in the first six years of life. The Group Health Medical Associates. N Engl J Med 1995;332:133-8.

9 Turner SW, Palmer U, Rye PJ, et al. Infants with flow limitation at 4 weeks: outcome at 6 and 11 years. Am J Respir Crit Care Med 2002;165: 1294-8.

10 Turner SW, Palmer L, Rye PJ, et al. The relationship between infant airway function, childhood airway responsiveness, and asthma. Am J Respir Crit Care Med 2004; 169:921-7.

11 Lowe LA, Simpson A, Woodcock A, and the NAC Manchester Asthma and Allergy Study Group, et al. Wheeze phenotypes and lung function in preschool children. Am J Respir Crit Care Med 2005; 171:231-7.

12 Silverman M, Wilson NM. Wheezing phenotypes in childhood. Thorax 1997;52:936-7.

13 Brooke AM, Lambert PC, Burton PR, et al. The natural history of respiratory symptoms in preschool children. Am J Respir Crit Care Med 1995; 152:1872-8.

14 Morgan WJ, Stern DA, Sherrill DL, et al. Outcome of asthma and wheezing in the first 6 years of life: follow-up through adolescence. Am J Respir Crit Care Med 2005;172:1253-8.

15 Saglani S, Malmstrom K, Pelkonen AS, et al. Airway remodeling and inflammation in symptomatic infants with reversible airflow obstruction. Am J Respir Crit Care Med obstruction. Am J

16 Hogg JC. Role of latent viral infections in chronic obstructive pulmonary disease and asthma. Am J Respir Crit Care Med 2001;164:S71-5.

17 Ball TM, Castro-Rodriguez JA, Griffith KA, et al. Siblings, day-care attendance, and the risk of asthma and wheezing during childhood. N Engl J Med 2000;343:538-43.

18 Sigurs N, Gustafsson PM, Bjarnason R, et al. Severe respiratory syncytial virus bronchiolitis in infancy and asthma and allergy at age 13. Am J Respir Crit Care Med 2005;171:137-41.

19 Stein R, Sherrill D, Morgan WJ, et al. Respiratory syncytial virus in early life and risk of wheeze and allergy by age 13 years. Lancet 1999;354:541-5.

20 O'Donnell DR, Openshaw PJ. Anaphylactic sensitization to aeroantigen during respiratory virus infection. Clin Exp Allergy 1998;28:1501-8.

21 Langley SJ, Goldthorpe S, Craven M, et al. Relationship between exposure to domestic allergens and bronchial hyperresponsiveness in non-sensitised, atopic asthmatic subjects. Thorax 2005;60:17-21.

22 Tortorolo L, Langer A, Polidori G, et al. Neurotrophin overexpression in lower airways of infants with respiratory syncytial virus infection. Am J Respir Crit Care Med, 2005;172, 233-7.

23 Chalmers GW, Macleod KJ, Little SA, et al. Influence of cigarette smoking on inhaled corticosteroid treatment in mild asthma. Thorax 2002; 57:226-30.

24 Chaudhuri R, Livingston E, McMahon AD, et al Cigarette smoking impairs the therapeutic response to oral corticosteroids in chronic asthma. Am J Respir Crit Care Med 2003;168:1308-11.

25 Tomlinson JE, McMahon AD, Chaudhuri R, et al. Efficacy of low and high dose inhaled corticosteroid in smokers versus non-smokers with mild asthma. Thorax 2005;60:282-7.

26 Oommen A, Lambert PC, Grigg J. Efficacy of a short course of parent-initiated oral prednisolone for viral wheeze in children aged $1-5$ years: randomised controlled trial. Lancet 2003;362: 1433-8.

27 Aurora P, Stocks J, Oliver C, on behalf of LCCF, et al. Quality control for spirometry in preschool children with and without lung disease. Am J Respir Crit Care Med 2004; 169:1 152-9.

28 Aurora P, Bush A, Gustafsson P, et al. Multiple breath washout as a marker of lung disease in preschool children with cystic fibrosis. Am J Respir Crit Care Med 2005;171:249-56. 